\title{
Energy Distribution of Secondary Electrons from Gold on Teflon-FEP
}

\author{
Carlos Alberto Fonzar Pintão \\ Departamento de Física, Faculdade de ciências, \\ Universidade Estadual Paulista, C. P. 473 \\ CEP 17013-360, Bauru, SP, Brasil.
}

\begin{abstract}
This paper presents results of the spectrum of energy of secondary electrons for the energies of perpendicularly incident electrons of $0.4 \mathrm{keV}, 2.0 \mathrm{keV}$, or $3.5 \mathrm{keV}$ in a gold surface deposited on a substratum of Teflon-FEP. Two samples of Teflon-FEP $(50 \mathrm{~nm})$ were used with deposition by sputtering gold layers with thicknesses of $2.5 \mathrm{~nm}$ and $50 \mathrm{~nm}$. The results show that the energy distribution depends on the energy of irradiation for the sample with the $2.5 \mathrm{~nm}$ gold layer, while no significant difference was observed for the sample with the $50 \mathrm{~nm}$ layer.
\end{abstract}

Key words - Secondary electron emission, emission yields, electron beam, energy distribution of secondary, gold, Teflon-FEP, spectrum of energy of secondary, crossover points, electron accelerator, polymers.

\section{INTRODUCTION}

THE emission of secondary electrons by solids irradiated with a mono-energetic beam of electrons is a technique that allows for the characterization of the physical and chemical properties of materials [1-8]. The secondary emission yield allows for identifying the state of the surface; for metals, this refers to the degree of oxidation, the presence of different chemical elements, the degree of machining, etc. New materials continue to be discovered, and there is a need to characterize them. Recent works in this direction have been published [9-17], illustrating its importance to new technological applications. The focus of research is often the experiments that determine the yield curves [18]; however, it is rare that measures are performed providing details or information concerning the secondary electron energy spectrum. Often, in accordance with specified needs, these curves are relative to an arbitrary unit of the emitted secondary electrons, or they are sometimes normalized. For insulating samples, it is still less common to find data about the energy distribution of the secondary electrons [19]. In the case of insulation, there is an additional experimental difficulty that involves the charges created during the emission process, which may be the reason that this type of measure is less common; however, more recently, some studies have presented research on the energy spectrum of the secondary electrons for metals and polymers [20-25].

The electrons emitted from a surface can be separated into two distinct groups: true secondary electrons and backscattered electrons. The first group consists of electrons with an energy range from $0 \mathrm{eV}$ to $50 \mathrm{eV}$. In general, these

Manuscript received on 13 July 2015, in final form 14 April 2016, accepted 19 June 2016. electrons have been released from the targeted material. The second group of electrons are released by incidents in which the material has experienced elastic or inelastic shocks and presents an energy higher than $50 \mathrm{eV}$, and these electrons are restricted to a maximum energy around that of the incident electron beam itself on the irradiated solid surface (usually greater than $100 \mathrm{eV}$ ).

This work presents the investigation of the distribution of energy of the secondary electrons of a solid composed of a gold layer deposited on the surface of a Teflon-FEP film, i.e., a deposited metal on an insulator, and these on the rear electrode. To determine the distribution of the energy of secondary electrons, a measuring system that was adapted to our experimental needs was used $[18,26]$ (see diagram in Figure 1). In addition, the method of retarding potential was applied [19,26], and an appropriate mathematical formalism for the measurement system was established, resulting in normalized energy distribution curves.

\section{THE MEASUREMENT SYSTEM}

Our laboratory apparatus $[18,26]$ (Figure 1) consisted of a modified version of the experimental setup used by Gross and Hessel [18, 27].

a) The scanning area of the collimated electron beam was larger than the diameter of the sample. The beam was aligned so that it was vertically incident on the sample surface. For reference, the beam could be deflected from its position above the sample surface to a position in which it was incident on the opening of the Faraday cup to facilitate the direct measurement of the full current produced by the primary incident electrons, $\mathrm{I}_{\mathrm{P}}$, for a given beam energy.

b) The grid-target geometry is planar $[5,6]$ with a transparency of approximately $80 \%$, and the collector is 
absent. For this reason, the measured current, $\mathrm{I}_{\mathrm{M}}$, is always obtained from a meter connected to the rear electrode of the sample. This can be polarized positively or negatively or can be grounded through a key system with blades.

c) The sample was deposited on an electrode that was free to vibrate with small amplitude oscillations so that the method of the vibrating capacitor was valid [29], and it was used to determine the surface potential (Vs).

d) To measure and record the electrical current, $I_{m}$, an electrometer (M) and a double-pen recorder, respectively, were used. The parameters of sensitivity $(\mathrm{S}=0.03)$ and resistance $\left(R_{E}=10^{7} \Omega\right)$ were selected to ensure that the RC time constant was of the order of $0.01 \mathrm{~s}$ because the capacitance of the sample, $\mathrm{C}$, was approximately $10^{-9} \mathrm{~F}$. These values ( $\mathrm{S}$ and $R_{E}$ ) are suitable for measuring the initial current using the pulse method, which is performed in a few seconds and does not accumulate charges capable of interfering with the secondary electrons emitted by the sample surface. The recording of the current, $\mathrm{I}_{\mathrm{m}}$, can be made digitally, but the double-pen recorder was chosen because $V_{S}$ was also measured. A recent study [30] showed that if Mylar samples are subjected to irradiation doses of the order of $10^{9} \mathrm{rad}$, a value much higher than those estimated in this study $\left(\sim 10^{2}\right.$ $\mathrm{rad})$, this alters the emission curves and shifts the value $\mathrm{E}_{\mathrm{II}}$.

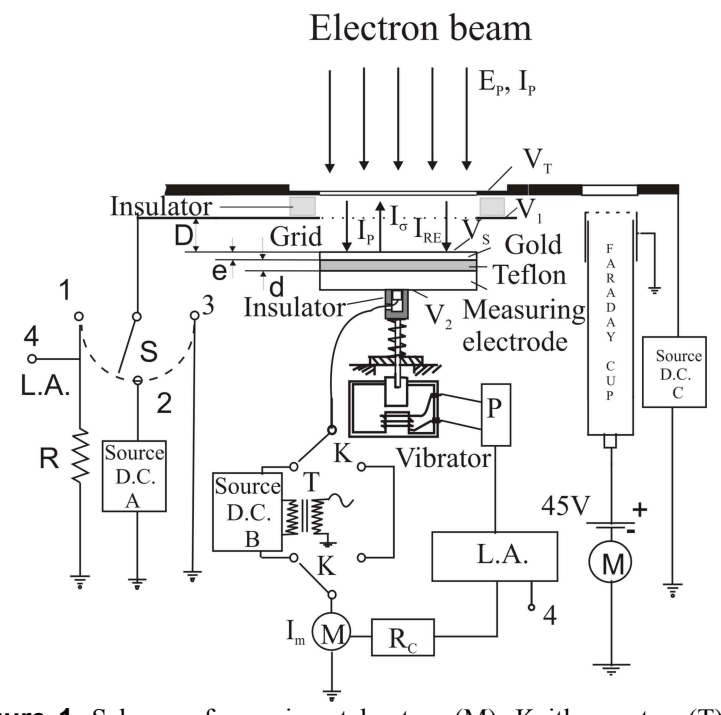

Figure 1. Scheme of experimental setup. (M): Keitley meter; (T): highinsulated coupling capacitor; (P): signal generator for magnetic coil; (L.A): lock-in amplifier; $(\mathrm{R})$ : measuring resistor for grid signals; $\left(\mathrm{R}_{\mathrm{C}}\right)$ : double-pen recorder; $\left(\mathrm{V}_{\mathrm{S}}\right)$ : surface potential; $\mathrm{S}$ and $\mathrm{K}$ : key polarization; $\left(\mathrm{V}_{1}, \mathrm{~V}_{2}\right.$, and $\left.\mathrm{V}_{\mathrm{T}}\right)$ : polarization potential for grid, electrode, and cover, respectively; ( $\mathrm{I}_{\mathrm{P}}, \mathrm{I}_{\mathrm{\sigma}}, \mathrm{I}_{\mathrm{m}}$, and $\left.\mathrm{I}_{\mathrm{RE}}\right)$ : current of electrons incident, emitted, measuring, and recaptured, respectively; $\left(E_{P}\right)$ : primary or incident energy of electrons; $(e, d)$ : thickness of gold layers and Teflon, respectively; (D): distance between surface and grid 1.

It should be noted that after each pulse, the dielectric target usually carried a small charge, which was either positive or negative. This necessitated discharging the sample surface between pulses, which was achieved by setting the electron beam to ensure that the conditions for the mechanism of selfregulation would be met [27]. The uniformity of the surface potential was examined between pulses to ensure that the sample surface was completely discharged and that any generated tertiary electrons had been removed. A rotary pump
(25 $\mathrm{m}^{3} /$ hour) was used to bring the system under a low vacuum, $0.13 \mathrm{~Pa}\left(10^{-3}\right.$ Torr), while a diffusion pump with a liquid nitrogen trap kept it under a high vacuum, $1.3 \times 10^{-4} \mathrm{~Pa}$ $\left(10^{-6}\right.$ Torr $)$.

\section{THE MEASUREMENT METHOD}

\subsection{Deducting the equation to construct the normalized energy distribution curve}

Before directly treating the method used to obtain the energy distribution of the secondary electrons for a formed solid of two layers of distinguished and homogeneous materials, the following must be considered:

1) For insulation, the surface potential $\left(V_{S}\right)$ can change with the time of irradiation, while for metals, which have a different behavior, this is not observed if the metals are grounded.

2) For insulation that is initially unloaded and grounded, $\mathrm{V}_{\mathrm{S}}>0$ when it is irradiated with an energy of $\mathrm{E}_{\mathrm{I}}<\mathrm{E}<\mathrm{E}_{\mathrm{II}}$, and $\mathrm{V}_{\mathrm{S}} \leq 0$ when it is irradiated with an energy of $\mathrm{E}<\mathrm{E}_{\mathrm{I}}$ or when $E>E_{I I}$. The values of $E_{I}$ and $E_{I I}$ are the energies for the first and second points of intersection, respectively, which refer to the yield value for the emission unit.

Based on this information, two possible cases that may occur during secondary emission can be analyzed.

First case: Negative surface potential $V_{S}$ and earthed grid 1 $\left(\mathrm{V}_{1}=0\right)$

Based on the currents shown in Figure 1, the current measurement for the electrometer will be:

$I_{m}=I_{p}+I_{\sigma}$, with $I_{R E}=0$

This implies that all secondary and backscattered electrons that escape from the sample surface can reach grid 1 .

Second Case: Positive surface potential $\mathrm{V}_{\mathrm{S}}$ and earthed grid $1\left(\mathrm{~V}_{1}=0\right)$.

The equation that expresses the current value measured, $I_{m}$, is:

$I_{m}=I_{p}+I_{\sigma}+I_{R E}$,

where $I_{m}$ is the measured current, $I_{p}$ is the current from the primary electrons, $I_{\sigma}$ is the sum of the current from the true secondary emission electrons $\left(I_{\delta}\right)$ and the backscattered electrons $\left(I_{\eta}\right)$, and $I_{R E}$ is the current from the recaptured electrons.

In this case, unlike the first case, not all secondary and backscattered electrons that escape the sample surface can reach grid 1. To determine the fraction of the electrons that are able to escape from the sample and reach grid 1, their energy distribution function, $g\left(E^{\prime}\right)$, for leaving the surface of the sample must be known, which will be used in the next considerations. Note that Figure 2 shows two characteristic peaks, which are the secondary and elastically reflected electrons; this curve is based on the experimental results and is illustrated schematically. 


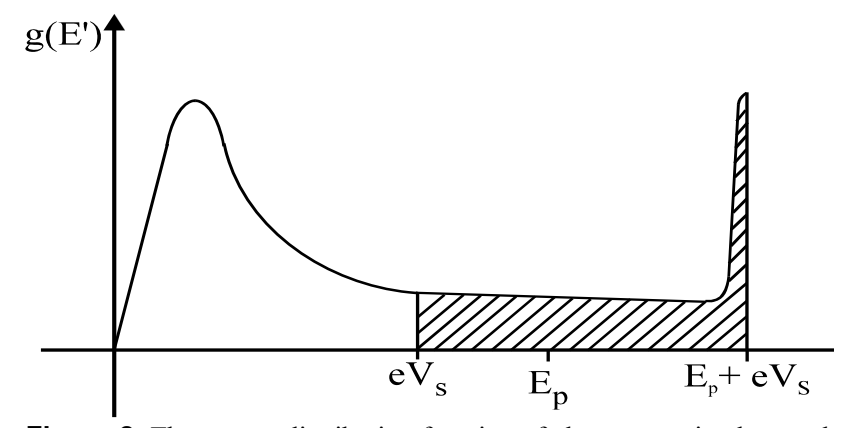

Figure 2. The energy distribution function of electrons emitted secondary plus backscattered, normalized.

The crosshatched area represents the fraction of electrons emitted from the sample surface with an energy greater than $e V_{S}$ that can reach grid 1.

$g\left(E^{\prime}\right)$ is defined as:

$g\left(E^{\prime}\right)=\frac{N\left(E^{\prime}\right)}{\int_{0}^{E e f} N\left(E^{\prime}\right) d E^{\prime}}$,

where $N\left(E^{\prime}\right) d E^{\prime}$ is the density of the secondary electrons $(S E)$ plus the backscattered electrons $(R E)$, leaving the surface with an energy between $E^{\prime}$ and $E^{\prime}+d E^{\prime}$, and $g\left(E^{\prime}\right) d E^{\prime}$ is the fraction of the density of electrons emitted with an energy between $E^{\prime}$ and $E^{\prime}+d E^{\prime}$.

From the normalization condition, we have:

$\int_{0}^{E e f} g\left(E^{\prime}\right) d E^{\prime}=1$

The term $E_{\text {ef }}$ that is used in this text is the effective energy electron reaching the sample; that is, $\mathrm{E}_{\mathrm{ef}}=\mathrm{E}_{\mathrm{p}}+\mathrm{eV}_{\mathrm{s}}$. Equation (4) can be arranged as:

$$
\begin{aligned}
& I_{\sigma}=I_{\sigma} \int_{0}^{E_{e f}} g\left(E^{\prime}\right) d E^{\prime}= \\
& =I_{\sigma} \int_{0}^{e V_{S}} g\left(E^{\prime}\right) d E^{\prime}+I_{\sigma} \int_{e V_{S}}^{E_{e f}} g\left(E^{\prime}\right) d E^{\prime}
\end{aligned}
$$

The fraction $\int_{0}^{e V_{S}} g\left(E^{\prime}\right) d E^{\prime}$ corresponds to $S E+R E$ in which electrons are not able to reach grid 1 because they do not have enough energy to overcome the potential difference between grid 1 and the sample surface $\mathrm{V}_{\mathrm{S}}$. The fraction $\int_{e V_{S}}^{E_{e f}} g\left(E^{\prime}\right) d E^{\prime}$ corresponds to electrons that have an energy higher than $e V_{S}$ and that can reach grid 1. Therefore, equation (5) can be written as:

$I_{\sigma}=-I_{R E}+I_{\sigma} \int_{e V_{S}}^{E_{e f}} g\left(E^{\prime}\right) d E^{\prime}$

Combining equations (2), (6), and $I_{\sigma}=-\sigma I_{p}$, from ref. [21], results in the following:

$$
\begin{aligned}
& I_{m}^{\prime}=I_{p}+\left[\left(-I_{R E}+I_{\sigma} \int_{e V_{S}}^{E_{e f}} g\left(E^{\prime}\right) d E^{\prime}\right)\right]+I_{R E} \\
& I_{m}^{\prime}=I_{p}\left\{1-\sigma\left[E_{e f}\right] \int_{e V_{S}}^{E_{e f}} g\left(E^{\prime}\right) d E^{\prime}\right\} \\
& \int_{e V_{S}}^{E_{e f}} g\left(E^{\prime}\right) d E^{\prime}=\frac{\sigma^{\prime}}{\sigma} \\
& \text { where } \sigma^{\prime}=1-\frac{I_{m}^{\prime}}{I_{P}}
\end{aligned}
$$

Equation (8) can also be expressed in terms of current:

$\int_{e V_{S}}^{E_{e f}} g\left(E^{\prime}\right) d E^{\prime}=\frac{1}{\left(I_{P}-I_{m}\right)}\left[I_{P}-I_{m}^{\prime}\right]$

where $I_{m}$ corresponds to the situation in which $I_{R E}=0$, and $I^{\prime}{ }_{m}$ corresponds to that in which $I_{R E} \neq 0$.

In maintaining $I_{P}$ as a constant and a varying $\mathrm{V}_{\mathrm{S}}$, equations (8) and (9) are a function of $\mathrm{V}_{\mathrm{S}}$. In practice, it is possible to vary $V_{S}$ through $V_{2}$ (see Figure 1). If the sample is metallic, $\mathrm{V}_{\mathrm{S}}$ coincides with $\mathrm{V}_{2}$; if it is an insulator and is initially discharged, it may also be considered almost equal to $V_{2}$ because $D>d$ (Figure 1). Thus, varying $V_{2}$ (positive) is equivalent to varying $V_{S}$. For each polarization, $V_{2}$ will have a different fraction of electrons with an energy greater than $\mathrm{eV}_{2}$ and that are capable of reaching grid 1. A similar situation is to keep $\mathrm{V}_{\mathrm{S}}=\mathrm{V}_{2}=0$ and to polarize grid 1 with $\mathrm{V}_{1}<0$. This was the procedure that was adopted for this paper [26].

When deriving equation (9) in relation to $E^{\prime}=e V_{S}>0$, we obtain:

$g\left(E^{\prime}\right)=\frac{1}{I_{p}-I_{m}} \frac{d I_{m}^{\prime}\left(e V_{S}\right)}{d\left(e V_{S}\right)}$

Experimentally, if we get $I_{m}^{\prime}$ as a function of $\mathrm{V}_{\mathrm{S}}$, then we can obtain $g\left(E^{\prime}\right)$.

For the portion of the emission curve in which the distribution of emitted electrons is in the energy range from $0 \mathrm{eV}$ to $50 \mathrm{eV}$ (secondary), as a function of the polarization of grid 1 , the current measurements are obtained by using current pulses of short durations. A fixed potential was generated by the $V_{F}$ filament emitter, and another fixed potential, $V_{2}$, was generated from the rear electrode sample stand. Since the sample must initially be discharged, $\mathrm{V}_{2}$ is initially the same as $\mathrm{V}_{\mathrm{S}}$. These potential values determine the beam energy of incident electrons, $E_{p}, E_{p}=e\left(V_{S}-V_{F}\right)$. The beam is then set, and measurements are made at this irradiation energy. The incident electron current striking the sample, $I_{P}$, is measured using the Faraday cup, and the same process is used to determine the other energies used in the study. A current pulse is applied to the sample, and the measured current output, $I_{m}$, is recorded in the rear electrode. Before beginning another measurement, the surface of the sample is discharged using the self-regulation method [28]. This procedure must be performed before each new measurement to ensure that the presence of the charge close to the surface does not interfere with the emission measurement; however, there is a potential difference between the polymer surface and grid 1 , which can be determined by measurement [29]. This value is zero in the case of used samples $\left(\mathrm{V}_{\mathrm{S}}=0 \mathrm{~V}\right)$. Grid 1 is polarized in a range of $+20 \mathrm{~V}$ to $-50 \mathrm{~V}$; thus, it is possible to determine the $I^{\prime}{ }_{m}$ current curves as a function of $\mathrm{V}_{1}$. The fraction of electrons that leaves the sample and can reach grid 1 is:

$$
\int_{-e\left(V_{1}-V_{S}\right)}^{E_{P}} g\left(E^{\prime}\right) d E^{\prime}=\frac{1}{I_{P}-I_{M}}\left[I_{P}-I_{m}^{\prime}{ }_{m}\right]
$$

where the same form before $I_{M}$ is the current corresponding to the situation in which $\mathrm{I}_{\mathrm{RE}}=0$, and $I_{m}^{\prime}$ is the measured current when $I_{R E} \neq 0$. Then, $V_{S}$ is the surface potential after 
the self-regulation mechanism has discharged the sample surface. This potential will be present at the beginning of each measurement. By deriving equation (11) in relation to $E^{\prime}=e V_{1}$, we obtain:

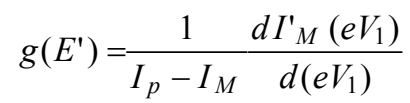

Equation (12) is the normalized energy distribution function for the electrons emitted from the surface of a solid. Because the polarization $\mathrm{V}_{1}$ is restricted to the range from $-50 \mathrm{~V}$ to $+20 \mathrm{~V}$, it will produce the conditions for the emission of secondary electrons with energies between $0 \mathrm{eV}$ and $50 \mathrm{eV}$. Details on how to obtain equations (11) and (12) can be viewed in reference [26], Chapter IV. Gross et al. provided another method for determining the parameters for the normalized distribution function [31].

\subsection{CURRENT CURVES ( $\left.I_{m}\right)$ AS A FUNCTION OF $V_{1}$}

Figures 3 and 4 provide a better understanding of the current curve $\left(I_{m}\right)$ as a function of $\mathrm{V}_{1}$ and the measurement method to get $g\left(E^{\prime}\right)$. In this method, it was decided to set $\mathrm{V}_{2}=0$ and $\mathrm{V}_{\mathrm{S}}=0$ and to change the value of the grid potential 1 $\left(\mathrm{V}_{1}\right)$ within a range of +20 to $-50 \mathrm{~V}$ to change $I_{R E}$ and then $I_{m}$. When $\mathrm{V}_{1}=0$, a case in which $I_{R E}=0$, the measured current corresponds to $I_{M}$ from equations (11) and (12). Two situations are identified when $\mathrm{V}_{1} \neq 0$ and $I_{R E} \neq 0$. The first occurs when $\mathrm{V}_{1}<0$ within the range of 0 to $-50 \mathrm{~V}$. In this case, the current $I_{R E}$ expresses all electrons with a lower energy $\mathrm{eV}_{1}$ and are unable to pass through grid 1 , and denominated of true secondary electrons. In this case, the total emission current $\left(I_{\sigma}=I_{\delta}+I_{\eta}\right)$ is modified because the $I_{\delta}$ changes in value, which implies that the measured current values $\left(I_{m}\right)$ are different. In this area of research, there is an arbitrary choice that makes the distinction between the electrons emitted in relation to their kinetic energy. The true secondary electrons represented by the emission current $\left(I_{\delta}\right)$ are electrons that have an energy between 0 and $50 \mathrm{eV}$, while the backscattering electrons $\left(I_{\eta}\right)$ are electrons emitted with an energy between $50 \mathrm{eV}$ up to $\mathrm{E}$, which is the energy of the incident beam. These facts ensure that by biasing grid 1, the current $I_{\delta}$ must change. The second situation occurs when $\mathrm{V}_{1}>0$ within the range of 0 to $+20 \mathrm{~V}$ in which the electric field lines can extract some secondary electrons from the surface of an insulating material, according to reports by Frederickson [32].

Young [33] established a relation between the penetration $\left(x_{d}\right)$ of the incident electrons and their energy $\left(E_{p}\right)$ from aluminum films, which can be used in assessing the penetration of other metals. This equation is

$x_{d}=\frac{0.011510^{-3}\left(E_{P}\right)^{1.35}}{\rho}$, in which $x_{d}$ is expressed in $\mathrm{cm}, E_{p}$ in $\mathrm{keV}, \rho$ in $\mathrm{g} / \mathrm{cm}^{3}$, and the constant in $\mathrm{g} / \mathrm{cm}^{2}(\mathrm{keV})^{-1.35}$.

The samples used have gold layers with $\mathrm{e}=2.5 \mathrm{~nm}$ and $\mathrm{e}=50$ $\mathrm{nm}$ deposited on the Teflon of a thickness of $\mathrm{d}=50 \mu \mathrm{m}$. Considering that the two samples of layers of gold are subjected to incident energies of $0.4,2.0$, or $3.5 \mathrm{keV}$ and $\rho=19.3 \mathrm{~g} / \mathrm{cm}^{3}$, the values $x_{d}$ from equation (13) are 1.73 $\mathrm{nm}, 15.2 \mathrm{~nm}$, or $26.3 \mathrm{~nm}$, respectively. Hence, for the gold layer of $\mathrm{e}=2.5 \mathrm{~nm}$, the incident with energy 2.0 and $3.5 \mathrm{keV}$ can reach the Teflon.

According to Seggern [34], electrons with $3 \mathrm{keV}$ penetrate $0.5 \mu \mathrm{m}$ in Teflon FEP on average, showing that the beam of incident electrons to the energy of $3.5 \mathrm{keV}$ is below what is required to exceed the thickness $(\mathrm{d}=50 \mu \mathrm{m})$ of the insulator.

Depending on the energy of the incidents (E) and the thickness of the gold layer (e), it can be observed that the current of the emitted $\left(I_{\sigma}\right)$ is changed such that the values of $I_{m}$ can have the same or the opposite direction of the current $I_{P}$. Curves 1 or 2 (see Figure $3 \mathrm{~b}$ ) exhibit the second crossover different values, i.e., $\mathrm{E}_{\mathrm{II}}=2.8 \mathrm{keV}$ and $7.2 \mathrm{keV}$ [26]. If the surface is irradiated with $\mathrm{E}$ between $\mathrm{E}_{\mathrm{I}}=20 \mathrm{eV}$ to $\mathrm{E}_{\mathrm{II}}$ and is valid for each of the two curves in Figure $3 \mathrm{~b}$, the current $I_{\sigma}$ at intensity or modulus is greater than that of the incidents electrons $\left(I_{P}\right)$. As a consequence, $I_{m}$ has the opposite direction of the $I_{P}$, as can be seen in Figure 4a. In this case, there are more electrons being emitted from the sample than that arrive on the sample, and for that reason, there is a current of electrons from earth to the rear electrode to compensate for the electrons emitted in a greater number on the surface. Therefore, they were represented by the plus sign for the positive charges on the gold surface and a minus sign for the negatives on the rear electrode of the sample. Observe that in the same situation of Figure $4 \mathrm{a}$, to continue irradiating the sample with $\mathrm{E}$ and between $\mathrm{E}_{\mathrm{I}}=20 \mathrm{eV}$ to $\mathrm{E}_{\mathrm{II}}$, these charges accumulate at the interface until the current $I_{\sigma}$ is equal to $I_{P}$ intensity, and the value of $I_{m}$ becomes zero. This evidence forms part of the self-regulation mechanism applied to the insulators with an emphasis that the energy of the incidents must have a value close to $E_{I I}$ so that $V_{S}$ is practically zero. In carrying out the assembly shown in Figure 4a with the polymer that did not undergo any irradiation of incidents, it appeared that there were negative charges inside. When adding a layer of gold to the earthed rear electrode, the insulating layer, which is a capacitor, has a potential difference between its surfaces interface (Gold-Teflon) and the rear electrode. When leaving the self-regulation mechanism to act until $\mathrm{V}_{\mathrm{S}}$ is zero, the negative charges of the insulation must be compensated for, which implies that an additional potential difference between gold and the Teflon opposite of the previous potential difference must be present. This alters the average energy of the secondary electrons most likely to be emitted $\left(\mathrm{E}_{\mathrm{M}}^{\prime}\right)$, and in this case, $\mathrm{E}_{\mathrm{M}}^{\prime}$ will increase. This occurs when the incident has a penetration $\left(x_{d}\right)$ smaller than the metal thickness. When the value of $x_{d}$ goes beyond the metal thickness and arrives in the Teflon, there are two 
possible cases. The first is when $\mathrm{E}$ is between $\mathrm{E}_{\mathrm{I}}$ and $\mathrm{E}_{\mathrm{II}}$, and the second is when $\mathrm{E}$ is greater than $\mathrm{E}_{\mathrm{II}}$. In the first case, there are positive charges generated in the Teflon, while in the second, there are negative charges. These charges can change the average energy of the secondary electrons most likely to be emitted. Due to the nature of the irradiated sample, which includes a metal and a polymer, this can be verified by the energy distribution function of the secondary $g\left(E^{\prime}\right)$. Seiler [4] stated that for metals, $1 \mathrm{eV}<\mathrm{E}_{\mathrm{M}}^{\prime}<5 \mathrm{eV}$, and two typical curves of the distribution of energy to the metal and insulator can be seen; however, this information applies to a sample (metal or insulator) in contact with the rear electrode, which is a different mounting from that used in this work.

As shown in Figure $4 \mathrm{~b}$, when applying $\mathrm{V}_{1}=-10 \mathrm{~V}$ in grid 1, $I_{m}$ has the same direction as $I_{P}$ because the intensity of the emission current, $I_{\sigma}$, in this new situation is lower than that of incident electrons. Once electrons have less energy than 10 $\mathrm{eV}$, they cannot go beyond grade 1 and return to the sample.

If the surface is bombarded with electron incidents with energy $\mathrm{E}$ larger than $\mathrm{E}_{\mathrm{II}}$, there is a current, $I_{m}$, with the same direction as $I_{P}$. In this case, the intensity of $I_{\sigma}$ is smaller than $I_{P}$. This means that there are fewer electrons being emitted, and for that reason, there is a flow of electrons from the rear electrode to earth to compensate for the smaller number of electrons being emitted by the surface relative to the incident. The bias applied in grid $1, \mathrm{~V}_{1}=-10 \mathrm{~V}$, further decreases to $I_{\sigma}=I_{\delta}+I_{\eta}$ because the emitted electrons with an energy less than $10 \mathrm{eV}$ does not have the energy to get through grid 1 and returns to the sample surface. The $I_{\delta}$ current intensity is lower compared to when $\mathrm{V}_{1}=0 \mathrm{~V}$. Therefore, $I_{\sigma}$ is lower for $\mathrm{V}_{1}=-10 \mathrm{~V}$ by changing $I_{m}$.

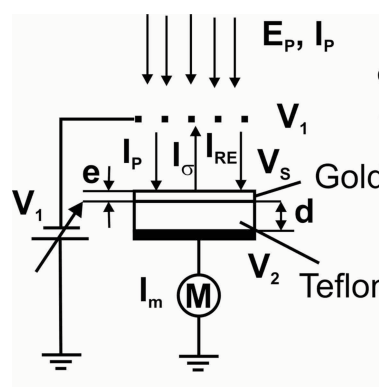

(a)

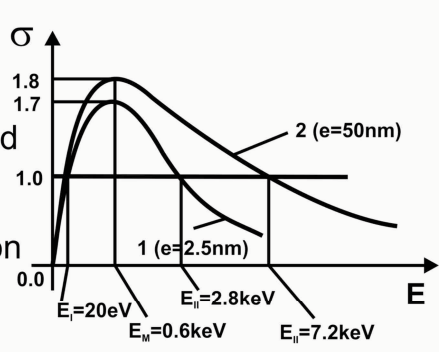

(b)
Figure 3. (a) Scheme of polarization potential for grid $1\left(\mathrm{~V}_{1}\right)$, electrode $\left(\mathrm{V}_{2}\right)$, and current of electrons incident $\left(I_{P}\right)$ emitted $\left(I_{\sigma}=I_{\delta}+I_{\eta}\right)$, measured $\left(I_{m}\right)$, and recaptured ( $I_{R E}$ ). (b) Outline of the total emission curve $(\sigma)$ as a function of the energy of the incident beam and experimental emission parameters [26].

According to Seiler [4], the maximum emission depth $(T)$ is about $T \cong 5 \lambda$, where $\lambda$ is the average depth escape on the maximum probability of a secondary electron being emitted. In metals, the $\lambda$ values are fixed at 0.5 to $1.5 \mathrm{~nm}$, so the maximum depth will be between 2.5 to $7.5 \mathrm{~nm}$. Thus, for the gold layer of $\mathrm{e}=2.5 \mathrm{~nm}$, the incidents with energy 2.0 or 3.5 $\mathrm{keV}$ can reach the insulating. It is estimated that for Teflon
FEP, $\lambda$ is $14.8 \mathrm{~nm}$ [26]. Hence, the emission maximum depth in the Teflon will be $74 \mathrm{~nm}$ in insulating, which can interfere with the secondary emission.

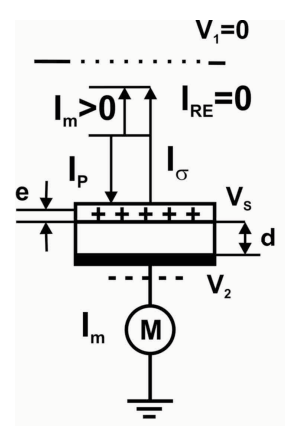

(a)

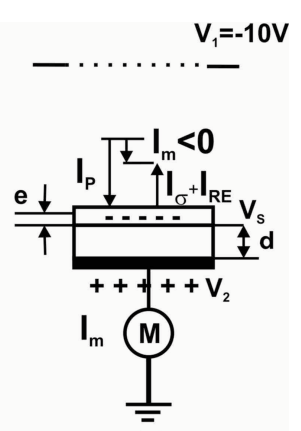

(b)
Figure 4. (a) Scheme of polarization potential for grid $1\left(\mathrm{~V}_{1}=0 \mathrm{~V}\right)$, electrode $\left(\mathrm{V}_{2}=0 \mathrm{~V}\right)$, and current of electrons incident $\left(I_{P}<0\right)$ emitted ( $I_{\sigma}=I_{\delta}+I_{\eta}>0$ ), measured ( $I_{m}>0$ ), and recaptured $\left(I_{R E}=0\right)$ to the interval of energy $\mathrm{E}_{\mathrm{l}}<\mathrm{E}<\mathrm{E}_{\mathrm{II}}$. (b) Polarization potential for grid $1\left(\mathrm{~V}_{1}=-10 \mathrm{~V}\right)$, electrode $\left(\mathrm{V}_{2}=0 \quad \mathrm{~V}\right), \quad$ and incident electrons $\left(I_{P}<0\right)$ emitted ( $\left.I_{\sigma}=I_{\delta}+I_{\eta}>0\right)$, measured $\left(I_{m}>0\right)$, and recaptured $\left(I_{R E} \neq 0\right)$. The energy used in the radiation is within the range $\mathrm{E}_{\mathrm{I}}<\mathrm{E}<\mathrm{E}_{\mathrm{II}}$.

\section{RESULTS AND DISCUSSION}

The curves in this section correspond to three different radiation energies, $\mathrm{E}_{\mathrm{p}}=0.4 \mathrm{keV}, 2.0 \mathrm{keV}$, or $3.5 \mathrm{keV}$, for two samples with gold layers of $2.5 \mathrm{~nm}$ or $50 \mathrm{~nm}$ thicknesses deposited on Teflon-FEP film with a $50 \mu \mathrm{m}$ thickness. In Figures 5, 6, and 7, the current curves are shown as a function of the potential difference between grid $1, V_{1}$, and the surface of the sample, $V_{2}+V_{S}$. Because the surface of the sample is a metal and, more importantly, because there is a polymer between the rear electrode and the layer of gold, there is a sufficient condition to apply the self-regulation method [27]. Then, we were able to offset the charges in the polymer and to set the potential of the gold surface to zero. Before applying the current pulse method, it was set to zero surface potential, or $\mathrm{V}_{\mathrm{S}}=0$.

Despite the small difference in the $\mathrm{I}_{\mathrm{m}}$ curves in Figure 5, the $I_{m}$ values corresponding to +10 volts or -50 volts are the same. These values are the focus in cases in which the coefficients or emission yield need to be determined [35, 36], but this will not be covered in this work. Figures 6 and 7 do not have current values of $I_{m}$ that are equal under the same grid 1 bias conditions; this is expressed in Figure 5, which shows that means as Gold and Teflon of different nature must be present. Thus, there must be true secondary electrons being emitted from the gold and from the Teflon, mainly because the incidents have greater energy and penetrate more deeply into the sample, according to the increases of $\mathrm{E}_{\mathrm{p}}$. Note that in Figure 7, while being irradiated with $3.5 \mathrm{keV}$, the sample with the $2.5 \mathrm{~nm}$ layer presents a current, $\mathrm{I}_{\mathrm{m}}$, which is less than zero when grid 1 is polarized to $+20 \mathrm{~V}$. This means that the incident energy is greater than that related to the second crossover point of gold, which is close to $2.8 \mathrm{keV}$ according to the literature [26]. Therefore, the net charge generated in the sample (gold layer on the polymer) must be negative. This 
is due to the presence of the polymer, which can accumulate electric charges; however, the positive or negative charges are controlled for a secondary emission yield curve of gold, meaning the values of energy, $\mathrm{E}_{\mathrm{I}}$ e $\mathrm{E}_{\mathrm{II}}$, which correspond to the first and second crossover points. In two other situations, seen in Figures 5 and 6, the opposite occurs: the net charge is positive, and the energy of the electrons that reach the sample is between $E_{I}$ and $E_{I I}$, which is relative to the secondary emission yield curve of the gold.

The small difference in current curves (see Figure 5), $\mathrm{E}_{\mathrm{p}}=0.4 \mathrm{keV}$, should occur because of the porosity of the surface of the Teflon-FEP. Some attempts were made to measure the electrical resistance of the gold on the surface of the Teflon-FEP for the two samples, and it was not possible to measure any resistance value in a sample of a $2.5 \mathrm{~nm}$ thickness. This indicates that it was a polymeric material with a porous surface.

Figures 8 to 13 were obtained using equation (12) and were derived from the current curves of the Figures 5, 6, and 7. The energy spectrum curves for emitted secondary electrons will be discussed below.

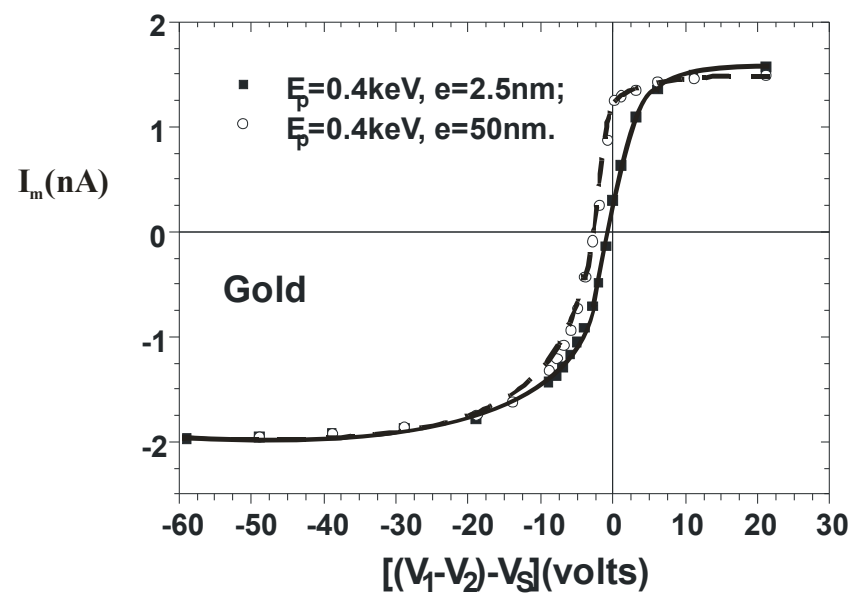

Figure 5. Current curves as a function of $\Delta \mathrm{V}$. Teflon-FEP sample with layers of gold of $2.5 \mathrm{~nm}$ and $50 \mathrm{~nm}$ thicknesses. $\mathrm{E}_{\mathrm{p}}=0.4 \mathrm{keV}$, and $\mathrm{I}_{\mathrm{p}}=2.25 \mathrm{nA}$

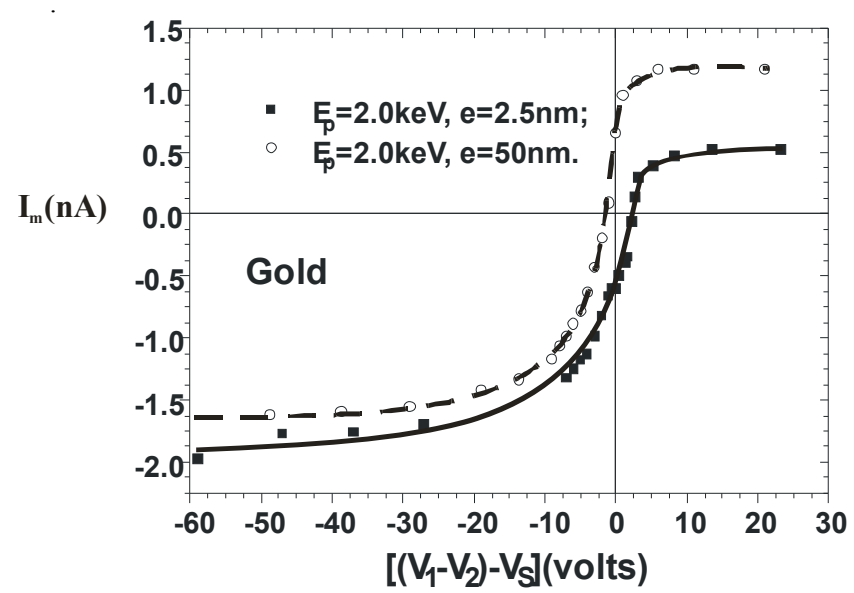

Figure 6. Current curves as a function of $\Delta \mathrm{V}$. Teflon-FEP sample with layers of gold of $2.5 \mathrm{~nm}$ and $50 \mathrm{~nm}$ thicknesses. $\mathrm{E}_{\mathrm{p}}=2.0 \mathrm{keV}$, and $\mathrm{I}_{\mathrm{p}}=2.25 \mathrm{nA}$.

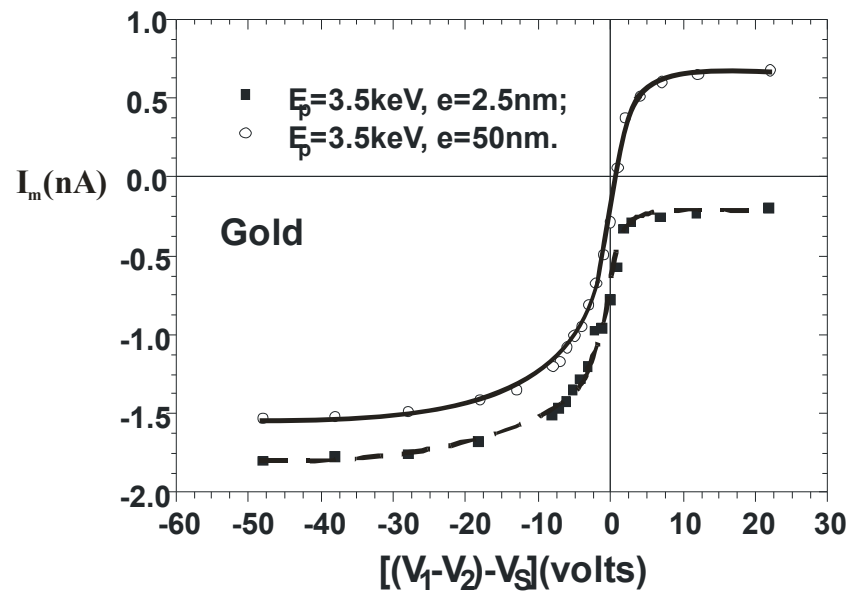

Figure 7. Current curves as a function of $\Delta \mathrm{V}$. Teflon-FEP sample with layers of gold of $2.5 \mathrm{~nm}$ and $50 \mathrm{~nm}$ thicknesses. $\mathrm{E}_{\mathrm{p}}=3.5 \mathrm{keV}$, and $\mathrm{I}_{\mathrm{p}}=2.25 \mathrm{nA}$.

The curve of the emitted secondary energy distribution $\left(g\left(E^{\prime}\right)\right)$ for $0.4 \mathrm{keV}$ irradiation is almost the same for the two gold layers studied, as shown in Figures 8 and 11. There is an intense peak corresponding to the gold emission spectrum with an average energy of the secondary electrons most likely to be emitted $\left(\mathrm{E}_{\mathrm{M}}^{\prime}\right)$ of $11 \mathrm{eV}$. This value is higher than that found in the literature [4]. This reinforces the explanation provided in section 3.2 , and this basic difference between this work and the literature is the experimental setups used. For the irradiation of $2.0 \mathrm{keV}$, the gold layer sample of $2.5 \mathrm{~nm}$, shown in Figure 9, presents a more intense peak in $8 \mathrm{eV}$ and a less intense peak at $12 \mathrm{eV}$. Each one of these peaks is relative to the distribution of the secondary electrons being emitted from gold and Teflon-FEP, respectively. Note that the difference between the energies related to the more intense peaks, which is also shown in Figure 9, is about $4 \mathrm{eV}$.

For this same energy radiation, i.e., $2.0 \mathrm{keV}$, we found that the sample with a golden layer of 50nm (Figure 12), showed that $\mathrm{E}_{\mathrm{M}}^{\prime}=10.8 \mathrm{eV}$. These are similar characteristics to the sample irradiated by the energy of $0.4 \mathrm{eV}$ (Figure 11) with the exception that the peak maximum emission intensity is smaller. This shows that the energy spectrum of secondary electrons depends on the depth of the penetration of incidents. Do not always there is a decays at the intensity of peak [19]. It is known that the gold emission curve has a maximum emission yield near $0.6 \mathrm{keV}$, and from there, the energy yield decreases. If an irradiation with electrons of $0.7 \mathrm{keV}$ was chosen, dependent on value emission yield in relation the energy $0.4 \mathrm{keV}$, the intensity of the peak would likely increase.

For the irradiation energy of $3.5 \mathrm{keV}$ (Figure 10), a similar behavior that is shown in Figure 9 was observed. In this case, the most intense peak was located at $9 \mathrm{eV}$, while the least intense was at $13 \mathrm{eV}$. It was observed that the difference between the energies related to the most intense peaks, which are shown in Figure 10, was approximately $4 \mathrm{eV}$.

The sample irradiated with energy $3.5 \mathrm{keV}$ with a gold layer thickness of $50 \mathrm{~nm}$ (Figure 13) presented a behavior quite similar for radiation energies and for 0.4 or $2.0 \mathrm{keV}$. In all of the cases illustrated in Figures 10, 12, and 13, the peak of maximum intensity from the distribution of secondary electrons shows that its value was lower for a higher irradiation energy. 


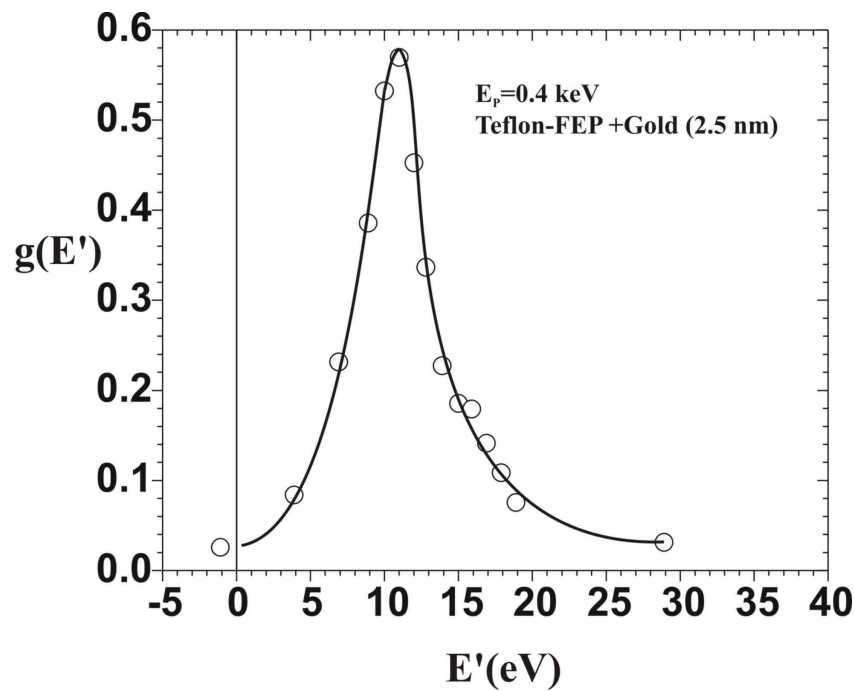

Figure 8. The energy distribution function normalized to the secondary electrons emitted by using the energy of $0.4 \mathrm{keV}$ radiation. Sample with a $2.5 \mathrm{~nm}$ gold layer.

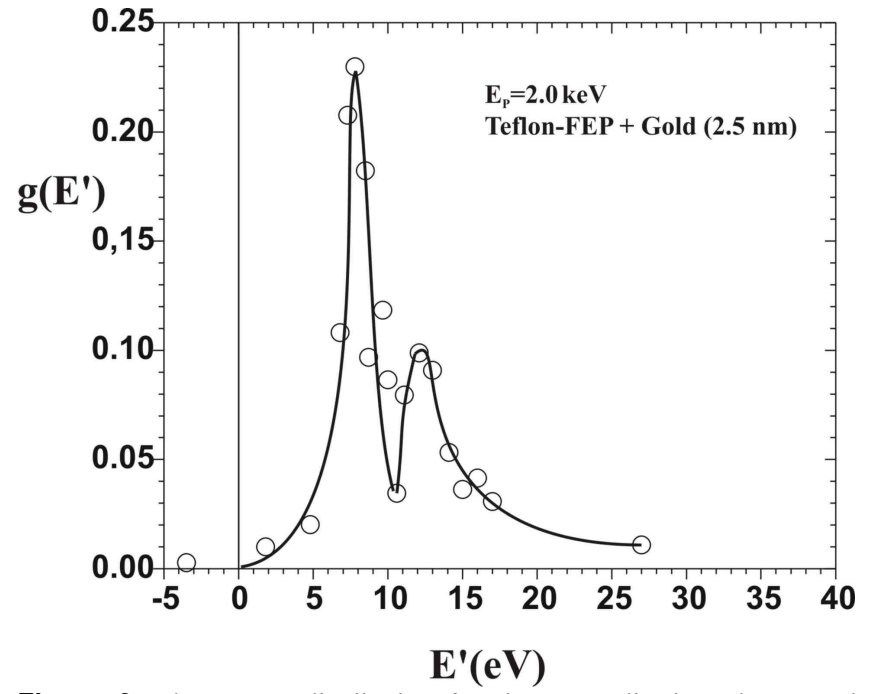

Figure 9. The energy distribution function normalized to the secondary electrons emitted by using the energy of $2.0 \mathrm{keV}$ radiation. Sample with a $2.5 \mathrm{~nm}$ gold layer.

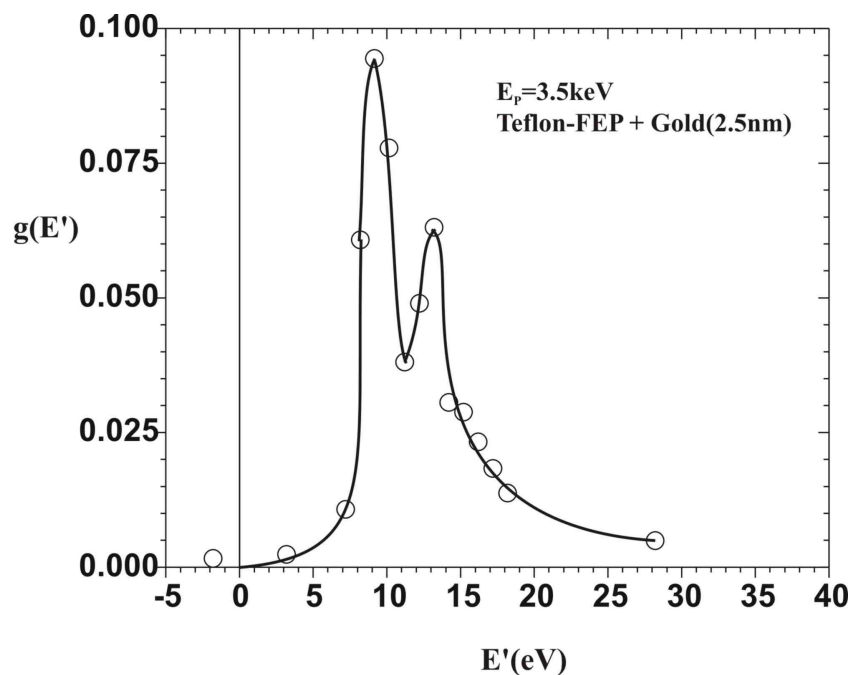

Figure 10. The energy distribution function normalized to the secondary electrons emitted by using the energy of $3.5 \mathrm{keV}$ radiation. Sample with a $2.5 \mathrm{~nm}$ gold layer.

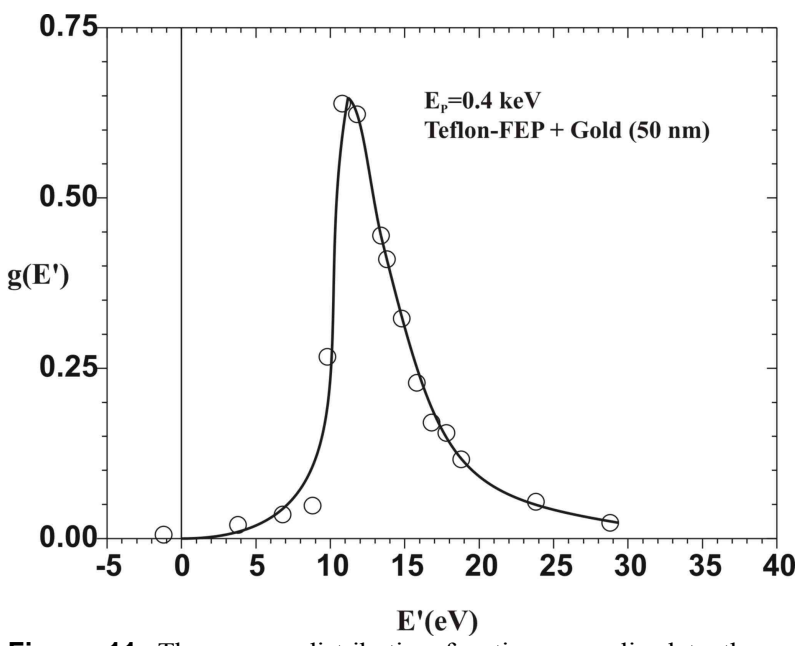

Figure 11. The energy distribution function normalized to the secondary electrons emitted by using the energy of $0.4 \mathrm{keV}$ radiation. Sample with a $50 \mathrm{~nm}$ gold layer.

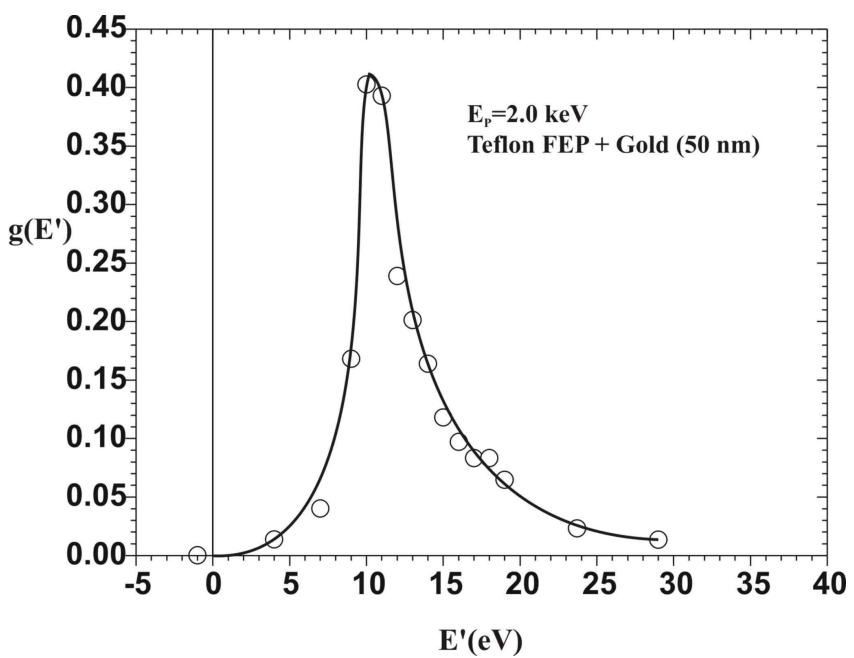

Figure 12. The energy distribution function normalized to the secondary electrons emitted by using the energy of $2.0 \mathrm{keV}$ radiation. Sample with a $50 \mathrm{~nm}$ gold layer.

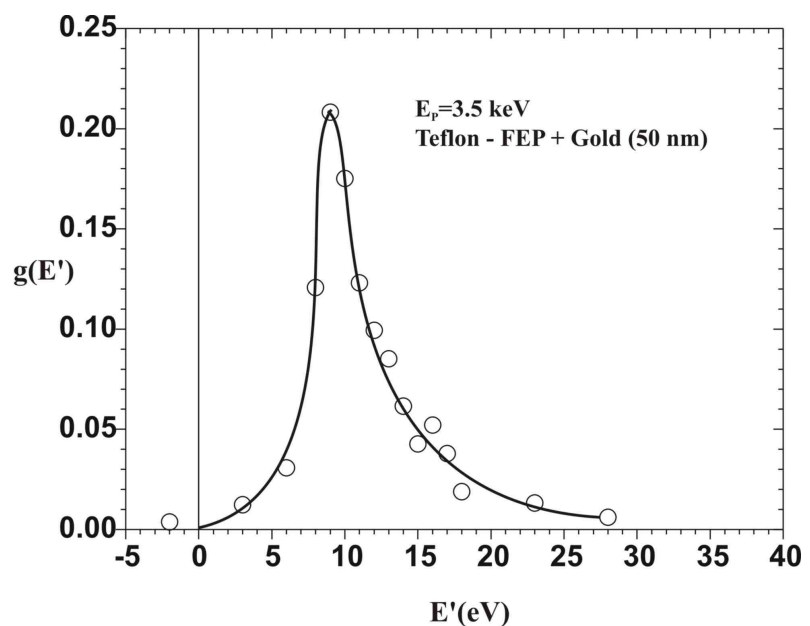

Figure 13. The energy distribution function normalized to the secondary electrons emitted by using the energy of $3.5 \mathrm{keV}$ radiation. Sample with a $50 \mathrm{~nm}$ gold layer. 


\section{CONCLUSION}

The results for both samples show that the normalized energy distribution function of the secondary electrons is strongly affected by the nature of the irradiated material, particularly in the case of the sample with the gold layer of a $2.5 \mathrm{~nm}$ thickness, for which $2.0 \mathrm{keV}$ or $3.5 \mathrm{keV}$ energies of radiation were used. In the case of the sample with a $50 \mathrm{~nm}$ layer of gold, for the energies of incident electrons, $0.4 \mathrm{keV}$, $2.0 \mathrm{keV}$, or $3.5 \mathrm{keV}$, there was a decrease in the peak intensity of the energy distribution function of secondary electrons when the incident energies of the electrons increased. The same was verified for the sample with the gold layer of $2.5 \mathrm{~nm}$; that is, there was a decrease in the peak intensity for the peaks of the energy spectrum curves according to the increase of energy for incident electrons.

\section{ACKNOWLEDGMENT}

The author thanks CNPq and FAPESP for their financial support and Professors Bernhard Gross, Roberto Hessel, and Guilherme F. L. Ferreira for having encouraged the implementation of the methodology used to obtain these measurements.

\section{REFERENCES}

[1] A. J. Dekker, Secondary Electron Emission, In: Solid State Physics, New York: Academic Press Inc., pp. 251-315, 1958.

[2] A. J. Dekker, Secondary Electron Emission, In: Solid State Physics, London and Basing stoke: Mac Millan \& Co, pp. 418-445, 1952.

[3] R. Kollath, Secondary Electron Emission of Solids Induced by Electron Bombardment, In: Encyclopedia of Physics, Berlin, Germany, Springer, Vol. 21, pp. 232-303, 1956.

[4] H. Seiller, "Secondary electron emission in the scanning electron microscope", J. Appl. Phys., Vol. 54, No. 11, pp. R1-R18, 1983.

[5] E. J. Sternglass, "Backscattering of kilovolt electrons from solids", Phys. Rev., Vol. 95, No. 2, pp. 345-358, 1954.

[6] N. R. Whetten, Secondary Electron Emission. In: Methods of Experimental Physics, New York: Academic Press, Vol. 4, Parte A, pp. 75-78, 1967.

[7] E. R. Boerwinkle, Measurements of Secondary Electron Emission from Dielectric Surfaces, Texas Tech University, Ph.D. thesis, 1988.

[8] T. L. Matskevich, "Secondary electron emission of some polymers", Fiz. Tverd. Tela Akad. Nauk., USSR, Vol. 1, p. 277, 1959.

[9] Z. Tan, Y.Y. Xia, X. Liu, and M. Zhao, "Mont-Carlo simulation of lowenergy electron scattering in PMMA using stopping powers from dielectric formalism", J. Microelectronic Eng., Vol. 77, No. 3-4, pp. 285-291, 2005.

[10] M. Boubaya and G. Blaise, "Charging regime of PMMA studied by secondary electron emission”, Europ. Phys. J. Appl. Phys., Vol. 37, pp. 79-86, 2007.

[11] M. Yasuda, K. Marimoto, Y. Kainuma, H. Kawata, and Y. Hirai, "Analysis of charging phenomena of polymer films on silicon substrates under electron beam irradiation", Jap. J. Appl. Phys., Vol. 47, No. 6, pp. 4890-4892, 2008.

[12] É.I. Rau, E. N. Evstaf'eva, and M. V. Adrianov, "Mechanisms of charging of insulators under irradiation with medium-energy electron beams", Phys. Solid. State., Vol. 50, No. 4, pp. 621-630, 2008.

[13] M. Dapor, M. Ciappa and W. Fichtner, "Monte Carlo modeling in the low-energy domain of the secondary electron emission of PMMA for critical dimension scanning electron microscopy", J. Micro/Nanolith MEMS MOEMS, Vol. 9, No. 2, 023001-1, 2010.
[14] M. Dapor, "Secondary electron emission yield calculation performed using two different Monte Carlo strategies", Nuclear Instruments and Methods in Physics Research B, Vol. 269, pp. 1668-1671, 2011.

[15] M. Ciappa, A. Koschik, M. Dapor and W. Fichtner, "Modeling secondary electron images for linewidth measurement by critical dimension scanning electron microscopy", Microelectronics Reliability, Vol. 50, pp.1407-1412, 2010.

[16] J. Cazaux, "A new model of dependence of secondary electron emission yield on primary electron energy for application to polymers", J. Phys. D: Appl. Phys., Vol. 38, pp. 2433-2441, 2005.

[17] J. Cazaux, "Secondary electron emission yield: graphite and some aromatic hydrocarbons", J. Phys. D: Appl. Phys., Vol. 38, pp. 2442$2445,2005$.

[18] R. Hessel, "Construction of an electron accelerator and its use for the study of the secondary emission in dielectric materials", São Carlos: USP-IFQSC, Ph.D. Thesis, 1990.

[19] N. R.Whetten and A. B. Laponsky, "Energy distribution of secondary electrons from MgO single crystals", Phys. Ver., Vol. 107, No. 6, pp. 1521-1524, 1957.

[20] B. Gross, C. A. F. Pintão and R. Hessel, "Field-Free and Field- Stimuled Electron Emission from Solids", Brazilian J. Phys. Vol. 29, No. 2, pp. 227-232, 1999.

[21] C. A. F. Pintão, "Mylar Secondary Emission-energy Distribution and Yields", IEEE Trans. Dielectr. Electr. Insul., Vol. 21, No. 1, pp. 311316, 2014.

[22] V. M. Agranovich, D. K. Daukeev, Yu.V.Konobeev, and S. Ya. Lebedev, "Study of the energy spectrum of secondary electrons arising from passage of $\alpha$ particles and fission fragments through thin foils", Soviet Phys., JETP, Vol. 30, No. 2, pp. 220-224, 1970.

[23] P. Riccardi, M. Pisarra1, A Cupolillo, M. C. Commisso, A. Sindona, R. A. Baragiola and C. A. Dukes, "Secondary electron emission spectra from clean and cesiated Al surfaces: the role of plasmon decay and data analysis for applications", J. Phys.: Condens. Matter, Vol. 22, pp. 1-6, 2010.

[24] Z. J. Ding, H. M. Li, R. Shimizu, and K. Goto, "on the Energy Distribution of Secondary Electrons Emitted from Metals", J. Surface Analysis, Vol. 15, No. 2, pp. 186-194, 2008.

[25] A. Shih, J. Yater, C. Hor and R. Abrams, "Secondary electron emission studies”, Applied Surface Sci., Vol. 111, pp. 251-258, 1997.

[26] C. A. F. Pintão, A new Arrangement to Determine the Coefficients of Emission and the Distribution of Energy of Secondary Electrons Emitted by Solids, São Carlos: USP-IFQSC, Ph.D. Thesis, 1996.

[27] R. Hessel and B. Gross, "Escape depth of secondary electrons from electron-irradiated polymers", IEEE Trans. Electr. Insul., Vol. 27, No. 4, pp.741-746, 1992.

[28] B. Gross and R. Hessel, "Electron Emission From Electron-irradiated Dielectrics", IEEE Trans. Electrl. Insul., Vol. 26, No. 1, pp. 18-25, 1991.

[29] R. A. Moreno and B. Gross, "Measurement of potential buildup and decay, surface charge density, and charging currents of corona-charged polymer foil electrets", J. Appl. Phys., Vol. 47, No. 8, pp. 3397-3402, 1976.

[30] D. L. Chinaglia, The Second Crossover in the Electronic Emission Curve Shift with the Absorbed Radiation Dose and its Implication, São Carlos: USP-IFQSC, Master degree in Applied Physics, 1992.

[31] B. Gross and R. G. Multhaupt, "A tribute to Gerhard M. Sessler on the occasion of his Sixtieth Birthday", IEEE Trans. Electr. Insul., Vol. 26, No. 1, pp. 3-14, 1991.

[32] A. R. Frederickson and S. Woolf, "Enhanced radiation shielding by space-charge fields in insulation slabs", J. Appl. Phys., Vol. 81, pp. 834$839,1997$.

[33] J. R. Young, "Penetration of electrons and ions in aluminum", J. Appl. Phys., Vol. 27, No. 1, pp. 1-4, 1956.

[34] H. Von Seggern, "Identification of TSC peaks and surface - voltage stability in Teflon FEP”, J. Appl. Phys., Vol. 50, pp. 2817-2821, 1979.

[35] C. A. F. Pintão and R. Hessel, "Total secondary-electron yield of metals measured by dynamic methods", J. Appl. Phys., Vol. 88, pp. 478-482, 2000.

[36] C. A. F. Pintão, "The emission and reduced yields of the Platinum and Teflon-FEP Secondary emission", Brazilian J. Vacuum Applications, Vol. 18, No. 2, pp. 56-58, 1999. 